\title{
Minor Changes in Gene Expression in the Mouse Preoptic Hypothalamic Region by Inflammation-Induced Prostaglandin $\mathbf{E}_{2}$
}

Ana-Maria Vasilache, Unn Örtegren Kugelberg, Anders Blomqvist and Camilla Nilsberth

\author{
Linköping University Post Print
}

\section{Tweet}

N.B.: When citing this work, cite the original article.

This is the pre-reviewed version of the following article:

Ana-Maria Vasilache, Unn Örtegren Kugelberg, Anders Blomqvist and Camilla Nilsberth, Minor Changes in Gene Expression in the Mouse Preoptic Hypothalamic Region by Inflammation-Induced Prostaglandin $E_{2}$, 2013, Journal of neuroendocrinology (Print), (25), 7 , 635-643.

which has been published in final form at:

http://dx.doi.org/10.1111/jne.12044

Copyright: Wiley-Blackwell

http://eu.wiley.com/WileyCDA/Brand/id-35.html

Postprint available at: Linköping University Electronic Press http://urn.kb.se/resolve?urn=urn:nbn:se:liu:diva-96460 
Minor changes in gene expression in the mouse preoptic hypothalamic region by inflammation-induced prostaglandin $\mathrm{E}_{2}$

Ana Maria Vasilache ${ }^{1,2}$, Unn Kugelberg ${ }^{1}$, Anders Blomqvist $1,{ }^{*}$, Camilla Nilsberth $^{1}$

${ }^{1}$ Division of Cell Biology, and ${ }^{2}$ Division of Transfusion Medicine, Department of Clinical and Experimental Medicine, Faculty of Health Sciences, Linköping University, S-581 85 Linköping, Sweden.

*Corresponding author. Address as above. Phone: +46 -10-1033193; Fax: +46 101033192; E-mail: anders.blomqvist@liu.se

25 pages, 2 figures, 3 tables

Short title: Minor changes in preoptic gene expression by $\mathrm{PGE}_{2}$

Key words: microsomal prostaglandin E synthase-1, prostaglandin $\mathrm{E}_{2}$, fever, preoptic region, laser-capture microdissection, whole genome microarray, heat-shock proteins.

Disclosure statement: The authors have nothing to disclose 


\section{Abstract}

We addressed the question to which extent inflammation-induced prostaglandin $\mathrm{E}_{2}$ $\left(\mathrm{PGE}_{2}\right)$ regulates gene expression in the central nervous system. Wild-type mice and mice with deletion of the gene encoding microsomal prostaglandin E synthase-1 (mPGES-1) which cannot produce inflammation-induced $\mathrm{PGE}_{2}$ were subjected to peripheral injection of bacterial wall lipopolysaccharide and killed after $5 \mathrm{~h}$. The median and medial preoptic nuclei, rich in prostaglandin E receptors, were isolated by laser capture microdissection, and subjected to whole genome microarray analysis. While the immune stimulus induced robust transcriptional changes in the brain, as seen by RT-qPCR on selected genes, only small PGE $\mathrm{P}_{2}$-dependent gene expression changes were observed in the gene array analysis, and for only two genes a pronounced differential expression between LPS-treated wild-type and mPGES-1 knockout mice could be verified by RT-qPCR. These were Hspa1a and Hspa1b, encoding heat shock proteins, which showed 2-3 times higher expression in wild-type mice than in knockout mice after immune challenge. However, the induced expression of these genes was found to be secondary to increased body temperature, because they were induced also by cage exchange stress which did not elicit $\mathrm{PGE}_{2}$ synthesis, and thus not induced per se by $\mathrm{PGE}_{2}$-elicited transcriptional events. Our findings suggest that inflammation induced $\mathrm{PGE}_{2}$ has little effect on gene expression in the preoptic region, and that centrally elicited disease symptoms, while being $\mathrm{PGE}_{2}$-dependent, occur as a result of regulation of neuronal excitability that is a consequence of intracellular, transcriptional independent signalling cascades. Our findings also imply that the profound changes in gene expression in the brain that are elicited by peripheral inflammation occur independently of $\mathrm{PGE}_{2}$ via a yet unidentified mechanism. 


\section{Introduction}

Peripheral inflammation induces profound changes in gene expression in the brain. The genes affected include those encoding immune responses, such as cytokines, chemokines, and adhesion molecules, but encompass also a variety of neuropeptides and other neurotransmitter related molecules (1-6). Peripheral inflammation also induces the production of prostaglandin $\mathrm{E}_{2}\left(\mathrm{PGE}_{2}\right)$ in the brain, being localized to brain endothelial cells (7-9), and it has been demonstrated that many of the centrally elicited disease symptoms associated with inflammatory condition are dependent on induced prostaglandin production. Thus, animals with genetic deletion of prostaglandin synthesizing enzymes display abolished or attenuated responses, such as fever, anorexia, hyperalgesia, social avoidance, and stress hormone release upon peripheral immune challenge (10-15), and these symptoms can also be alleviated by pharmacologic prostaglandin inhibition (16). However, it remains unclear to what extent the described changes in gene expression in the brain parenchyma (1-6) are a consequence of the induced prostaglandin production, or whether they occur independently, and hence to what extent these transcriptional events are involved in the development of the sickness syndrome. While the most rapidly developing sickness symptoms, such as fever that can be recorded within 15-20 min after a peripheral immune challenge $(17,18)$, are likely to be elicited by mechanisms that do not require protein neosynthesis (18), it is conceivable that the maintenance of the sickness symptoms may involve transcriptional regulation, either directly within cells that display a receptor mediated response to prostaglandins, or indirectly in cells affected by the former ones.

Here we address the question as to whether transcriptional regulation in the brain upon peripheral immune challenge is regulated by induced synthesis of $\mathrm{PGE}_{2}$. 
We made use of the fact that mice with deletion of microsomal prostaglandin Esyntase-1 (mPGES-1), the terminal inducible PGE 2 synthesizing enzyme (19), do not produce $\mathrm{PGE}_{2}$ upon immune challenge $(10,20)$. We compared the gene expression in these mice after peripheral injection of bacterial wall lipopolysaccharide (LPS) with that in LPS treated wild type littermates with intact mPGES-1, permitting us to examine the specific role of induced $\mathrm{PGE}_{2}$, as other inflammation and $\mathrm{PGE}_{2}$ independent mediators would be the same. Data were obtained by unbiased microarray analysis on the preoptic hypothalamus, a $\mathrm{PGE}_{2}$-receptor (EP) rich area (21) that also has been shown to be critical for the febrile response (22), and were verified by quantitative RT-PCR on independent samples. To identify effects that may have been secondary to the increased body temperature in wild-type mice in response to the immune challenge, selected genes were also examined after emotional stressinduced, and prostaglandin independent, hyperthermia.

\section{Materials and Methods}

\section{Animals}

Male mPGES-1 $1^{+/+}$and mPGES-1 ${ }^{-/-}$mice on a DBA1/lacJ background (20) were generated by breeding heterozygous littermates. The mice were weight- and agematched, and kept under similar environmental conditions with one mouse per cage and with water and food available ad libitum.

All the experimental procedures were approved by the Animal Care and Use Committee at the Linköping University. 


\section{Immune challenge with LPS}

Mice were briefly restrained and injected intraperitoneally (ip) with either $100 \mu \mathrm{l}$ saline or $120 \mu \mathrm{g} / \mathrm{kg}$ LPS (Sigma, St. Louis, MO; 0111:B4, 1mg/ml) in $100 \mu$ l saline. This dose evokes a centrally elicited sickness syndrome, with robust fever $(10,23$, 24), pronounced anorexia (12), and strong hypothalamus-pituitary-adrenal axis activation (13). All injections were done at the same time point during the light-on phase. Mice were killed by asphyxiation with $\mathrm{CO}_{2}$ and briefly perfused with $100 \mathrm{ml}$ saline prior to brain dissection at 40, 90, 180, and 300 minutes, respectively, after LPS injection.

\section{Cage exchange-induced stress}

A hyperthermic stress response was induced by letting two male mice exchange their home cages. As control, animals were lifted up but placed back into their own home cage. The animals were killed 100 min after the cage exchange.

\section{Tissue preparation}

For a kinetic study of the expression of COX-2 and mPGES-1 after LPS injection, and for the cage exchange study, the whole hypothalamus and striatum were rapidly dissected and stabilized in RNAlater (Invitrogen, Carlsbad, CA) overnight at $4^{\circ} \mathrm{C}$. The RNA was extracted with RNeasy Mini kit (Qiagen, Hilden, Germany), according to the manufacturers' protocol. The average amount of extracted RNA per sample was over 50ng/ $\mu$ l. RNA quality and quantity control was done on NanoDrop 1000 (NanoDrop, Wilmington, DE). 
For microarray analysis the whole brain was frozen in OCT embedding (VWR, Bridgeport, $\mathrm{NJ}$ ) with isopentane on dry ice and stored at $-70^{\circ} \mathrm{C}$ until sectioning at 8 $\mu \mathrm{m}$ on a cryostat. Six to eight successive sections were picked up on HistoGene LCM slides (Applied Biosystems, Foster City, CA) and stored immediately at $-70^{\circ} \mathrm{C}$. Every $7^{\text {th }}$ or $9^{\text {th }}$ sections were used as controls. The slides were rapidly stained using the HistoGene LCM Frozen Section Staining Kit (Applied Biosystems). One slide at a time was treated as follows: thawing in room temperature, $75 \%$ ethanol, distilled water, staining solution, distilled water, 75\%, 95\%, and 100\% ethanol (each step for 20-30 min), and finally xylene, in which the slides were stored 30 min to $1 \mathrm{~h}$ until microdissection with PixCell ${ }^{\circledR}$ II (Applied Biosystems) onto CapSure ${ }^{\mathrm{TM}}$ HS LCM caps (Applied Biosystems), using landmarks for selecting the median and medial preoptic nucleus described previously (21). The caps were placed in $0.5 \mathrm{ml}$ microcentrifuge tubes containing 30 $\mu$ l RNA Extraction Buffer. After a brief centrifugation the tubes were stored at $-70^{\circ} \mathrm{C}$. The RNA extraction was done with PicoPure $^{\mathrm{TM}}$ RNA Isolation Kit (Applied Biosystems) according to the manufacturer's protocol. RNA quality and quantity control was performed on an Agilent 6000 Pico Bioanalyzer (Agilent, Santa Clara, CA).

\section{Telemetric recordings}

The mice were anaesthetized with isoflurane ( $4 \%$ ) and implanted in the peritoneal cavity with G2 E-mitter transmitters (Mini Mitter, Bend, OR) that allow continuous temperature and activity measurements. The animals were allowed to recover for at least 1 week before any recordings were made. Prior to LPS injections or cage exchange, the basal temperature of each mouse was recorded for $72 \mathrm{~h}$ to assure that they displayed normal body temperature with normal circadian variation. 


\section{RNA amplification and microarray hybridization}

RNA was amplified by a two-round amplification using RiboAmp ${ }^{\text {Plus }}$ RNA Amplification Kit (Molecular Devices, Sunnyvale, CA) according to the manufacturer’s protocols. Poly-A control RNA (GeneChip® Poly-A RNA Control Kit; Affymetrix, Santa Clara, CA) was added to the RNA before amplification. The amplified RNA was biotin-labelled using TURBO labeling ${ }^{\mathrm{TM}}$ kit according to the manufacturer's protocol (Molecular Devices). The purified biotin-labelled amplified RNA was fragmented using 5x fragmentation buffer (200mM Tris-acetate, pH 8.1, $500 \mathrm{mM}$ KOAc, $150 \mathrm{mM} \mathrm{MgOAc}$ ) at $94^{\circ} \mathrm{C}$ for $10 \mathrm{~min}$ followed by $4^{\circ} \mathrm{C}$ for $2 \mathrm{~min}$. The hybridization mix was prepared according to the TURBO labeling ${ }^{\mathrm{TM}}$ kit manual using GeneChip ${ }^{\circledR}$ Hybridization, Wash, and Stain Kit (Affymetrix). The mix was thereafter hybridized to GeneChip ${ }^{\circledR}$ Mouse Genome 4302.0 Arrays in a GeneChip ${ }^{\circledR}$ Fluidics Station 450 (Affymetrix) using GeneChip ${ }^{\circledR}$ Hybridization, Wash, and Stain Kit (Affymetrix) and the chips were scanned in a GeneChip ${ }^{\circledR}$ Scanner 3000 (Affymetrix).

\section{Microarray analysis}

After quality control the raw image data were converted to CEL files using Affymetrix GeneChip Operating Software (GCOS). The CEL files were imported to GeneSpring GX software (Agilent) for analysis. Three different algorithms were used for data normalization: the Robust Multiarray Average (RMA) (25), the Guanine Cytosine RMA (GCRMA) (26), and the Probe Logarithmic Intensity Error (PLIER) estimation (27). Data was filtered by expression, keeping the entities where at least 2 out of 10 samples had values between the 30 and $100^{\text {th }}$ percentile in the raw data. Statistical analysis was performed using unpaired $t$-test with unequal variance 
comparing the mPGES-1 ${ }^{+/+}$mice with $\mathrm{mPGES}-1^{-/-}$mice. Genes were filtered on Volcano plot, cut-off was set at $P \leq 0.05$ and a fold change $\geq 1.5$, and the genes that met the above criteria using RMA, GCRMA and PLIER were taken forward for additional study (28).

\section{Reverse transcription - quantitative PCR}

The RNA was transcribed to cDNA with the High Capacity cDNA Reverse Transcription kit (Applied Biosystems). Pre-amplification kit was carried out with TaqMan PreAmp Master Mix kit and the TaqMan Low Density Arrays (TLDAs) format 48 (for 46 target genes and 2 controls) (Applied Biosystems). The RT-qPCR reaction was performed using TaqMan Gene Expression Master Mix and specific TaqMan inventoried gene assays (Applied Biosystems) (Table 1). Data were analysed using the $\Delta \Delta \mathrm{Cq}$ method (Cq, quantification cycle according to the MIQE guidelines) with GAPDH as reference gene. Each gene was normalized against the reference gene $(\Delta \mathrm{Cq})$ both in the stimulated and in the control group as $\mathrm{Cq}_{\text {target gene }}-\mathrm{Cq}$ reference gene, and the $\Delta \Delta \mathrm{Cq}$ as the difference between the $\Delta \mathrm{Cq}_{\text {stimulated }}-\Delta \mathrm{Cq}_{\text {control. The gene }}$ expression changes were analysed as fold change values: $2^{-\Delta \Delta \mathrm{Cq}}$. The initial cDNA concentration for both TLDAs experiment and individual RT-qPCRs were chosen to get a $\mathrm{Cq}_{\text {reference gene }}$ in the range of 13 to 20 cycles, and accepted $\mathrm{Cq}_{\text {target gene }}$ less than 35 cycles.

\section{Statistical analyses}

Statistical significance of the RT-qPCR data was determined using the $t$-distribution. The SEM for fold differences was obtained by first calculating the SD for each of the two groups that were compared ( $\mathrm{s}_{1}$ and $\mathrm{s}_{2}$ with $\left(\mathrm{n}_{1}-1\right)$ and $\left(\mathrm{n}_{2}-1\right)$ degrees of freedom), 
and then applying these values in the following formula: $\left[\left(\mathrm{s}_{\mathrm{p}}{ }^{2}\left(1 / \mathrm{n}_{1}+1 / \mathrm{n}_{2}\right)\right]^{0.5}\right.$ in which $\mathrm{s}_{\mathrm{p}}^{2}=\left[\mathrm{s}_{1}^{2}\left(\mathrm{n}_{1}-1\right)+\mathrm{s}_{2}^{2}\left(\mathrm{n}_{2}-1\right)\right] /\left(\mathrm{n}_{1}+\mathrm{n}_{2}\right)$.

Activity and temperature curves were analysed by a two-way ANOVA followed by Bonferroni post-hoc test with correction for multiple comparisons.

\section{Results}

\section{Temporal course of COX-2 and mPGES-1 expression}

In order to find a relevant time point for the gene expression study we examined the dynamics of the gene expression of the prostaglandin synthesizing enzymes $\mathrm{COX}_{2}$ and mPGES-1 in the hypothalamus during $5 \mathrm{~h}$ after LPS injection. Previous experiments using the current experimental model have shown that the mice rapidly generate a fever-response that lasts for up to seven hours (10). COX 2 mRNA showed a rapid induction that peaked at 90 minutes (fold change 15.87, SEM 0.297, $P<$ 0.001), after which it slowly declined but was still clearly elevated at $5 \mathrm{~h}$. The expression of mPGES-1 mRNA started to increase between 40-90 minutes postinjection, to display the highest value at $5 \mathrm{~h}$ (fold change 4.17, SEM 0.223, $P<0.001$ ) (Figure 1A). From previous studies it is known that following peripheral LPSinjection, $\mathrm{PGE}_{2}$ levels in the brain peak at $3 \mathrm{~h}$, while protein levels of COX-2 and mPGES-1 continue to increase to peak at $5 \mathrm{~h}$ and $12 \mathrm{~h}$, respectively (29). To assure that we would monitor transcriptional changes elicited by high $\mathrm{PGE}_{2}$-levels and that the time point also coincided with the full display of various $\mathrm{PGE}_{2}$-dependent sickness symptoms $(10,12,13)$ we selected $5 \mathrm{~h}$ after the LPS injection for the microarray study. While the time course study was done on tissue from the whole hypothalamus, and the microarray analysis on the preoptic region only, there is no evidence that induction of $\mathrm{PGE}_{2}$ synthesizing enzymes should differ temporally 
between different regions (30). Hence data obtained from the time course study were considered representative also for the more restricted region examined in microarray analysis.

\section{Microarray analysis of differences in gene expression between LPS challenged} mPGES-1 ${ }^{+/+}$and $\mathrm{mPGES}-1^{-/-}$mice

Microarray analysis of the whole mouse genome on Laser Capture Microdissected (LCM) material from the preoptic hypothalamic region of 5 LPS-treated mPGES-1 ${ }^{+/+}$ and 5 LPS-treated mPGES-1 ${ }^{-/}$showed that 253 unique genes displayed more than 1.5fold difference between the two genotypes (Supplementary Table 1). Three transcripts displayed a higher expression in mPGES-1 ${ }^{-/-}$mice than in $\mathrm{mPGES}-1^{+/+}$mice, whereas the remaining 250 genes were expressed in higher amounts in $\mathrm{mPGES}-1^{+/+}$mice. The majority of the genes belonged to neuronal and cAMP dependent pathways, but no pathways were significantly changed in an integrated pathway analysis (Ingenuity Pathway Analysis System; Ingenuity System, Redwood City, CA).

\section{RT-qPCR for microarray validation}

Validation of the microarray data was performed on all the genes that had a fold change $>2$ at $P<0.05$, and for selected genes of special interest (cAMP signalling; neuronal signalling like GABA receptors, neuropeptides; and genes for synaptic vesicle transport pathways) that had a fold change of at least 1.5 at $P<0.01$ (Table 2). Data are based on 6 animals of each genotype (mPGES- $1^{+/+} / \mathrm{mPGES}-1^{-/-}$) and treatment (LPS/saline). A 48 format Taqman Low Density Array RT-qPCR (Applied Biosystems) was run on LCM dissected preoptic material taken from animals different from those used for the microarray analysis. 
The results (Table 2) showed that the expression of only few of the examined genes differed between genotypes. Four of these, Anks1b (encoding a multi-domain protein that interacts with amyloid beta protein precursor), Calm1 (encoding a calcium buffering protein, calmodulin 1), Fam179b (encoding a protein with unknown function), and Rab40b (encoding a protein suggested to be involved in regulating secretory vesicles) displayed lower expression in LPS treated wild-type mice than in LPS treated knock-out mice, suggesting that $\mathrm{PGE}_{2}$ down-regulated their expression, which was contrary to the microarray data. However, this down-regulation was verified only for Fam179b, which showed lower expression after LPS injection compared with saline injection in wild-type mice, but not in knock-out mice. Overall, the effect of LPS-treatment on the selected genes was small, with only 3 genes, Hspa1a, to be described below, Rab40b, and Pdzd2 (encoding a protein that bind the C-termini of transmembrane receptors or ion channels) displaying LPS-induced upregulation, although small, when compared to $\mathrm{NaCl}$ injected mice (Table 2).

The largest difference in expression between LPS treated wild type and mPGES-1 knock-out mice was seen for Ptges, encoding mPGES-1, and included as control for sensitivity and accuracy of the genotyping, and Hspa1a, encoding a heat shock protein (HSP), which both were upregulated in LPS-treated wild-type mice (Table 2). Hspa1b, which shares $99 \%$ structural homology with Hspa1a, was analysed separately and was also found to show higher expression in LPS treated wild-type mice than in LPS treated knock-out mice (Table 3).

Because none of the genes that were selected based on the outcome of the microarray analysis was strongly upregulated, being in contrast to previous microarray analysis of the effect of LPS on hypothalamic gene expression (2), we performed an additional analysis on the same laser capture dissected material as used 
above of a few genes known to be strongly regulated by LPS. These genes, Ptgs2 (encoding Cox-2), Lcn2 (encoding lipocalin-2), and Cxcl10 all showed prominent upregulation, for some of the genes several 100-fold (Table 3), consistent with previous results $(2,6,24)$.

\section{Relationship between HSPs and mPGES-1}

The HSPs were up-regulated at a later time point than mPGES-1 (Figure 1B), which might suggest that the HSPs were regulated by $\mathrm{PGE}_{2}$, the product of mPGES-1. To further examine this potential relationship we compared the gene expression patterns between an EP rich (the hypothalamus) and an EP low (the striatum) expressing region $(31,32)$ in the same animal (Figure 1C). We found that mPGES-1 and PGE $2^{-}$ receptor subtype $3\left(\mathrm{EP}_{3}\right)$, as expected, showed higher expression in the hypothalamus than the striatum, and that LPS treatment further enhanced this difference for mPGES1. Hspa1a, but not Hspa1b showed higher expression in the hypothalamus than in the striatum (Figure1D), but whereas Hspa1b displayed a higher hypothalamus/striatum ratio after LPS than in naïve mice, the opposite was found for Hspa1a, i.e. patterns that were not consistent with what was expected had it been directly regulated by mPGES-1 induced PGE 2 .

\section{Cage exchange-induced stress hyperthermia induces HSPs}

Considering the data above, and since mPGES- $1^{+/+}$mice but not $\mathrm{mPGES}-1^{-/-}$mice display fever after LPS challenge, we tested if the difference in expression of the HSPs was a consequence of increased body temperature rather than increased levels of $\mathrm{PGE}_{2}$. We therefore subjected male mice of both genotypes to an emotional stress by letting them change cages (33). Their reaction to this procedure is increased motor 
activity and increased body temperature (Figure 2A, B). RT-qPCR analysis showed up-regulation of both HSPs transcripts, 100 min after the mice had been moved to each other's cage, with expression levels being close to identical between wild-type and mPGES-1 ${ }^{-/-}$mice, whereas the expression of the PGE 2 -synthesizing enzymes COX-2 and, in the wild-type mice, mPGES-1 was unaffected (Figure 2C). Thus, the HSPs were induced following emotional stress-evoked hyperthermia in the absence of induced $\mathrm{PGE}_{2}$-synthesis.

\section{Discussion}

In this unbiased gene expression study, examining the whole mouse genome, we show that inflammation-induced $\mathrm{PGE}_{2}$ induces only small changes in gene expression in the brain, even in a region rich in EP receptors such as the preoptic region of the hypothalamus (21, 31, 32). This is surprising considering that $\mathrm{PGE}_{2}$ mediates many of the centrally elicited sickness symptoms characteristic for inflammatory diseases.

Thus, animals devoid of mPGES-1, resulting in inability to produce $\mathrm{PGE}_{2}$ in response to inflammatory stimuli $(10,18)$, do not display fever, and show attenuated anorexia, HPA-response, and conditioned place aversion upon inflammatory challenge $(10,12$, 13, 34), and cyclooxygenase inhibition alleviates these disease symptom and behavioural responses (16). Notably, while sickness responses to peripheral inflammation are absent or attenuated in mPGES-1 knockout mice, these mice display similarly increased cytokine levels in plasma (13) and induced cytokine mRNA levels in brain and peripheral organs (5) as wild-type mice, indicating that the more general features of the immune response evoked by inflammatory stimuli remain intact in the knockout mice. 
Previous work with microarray analysis has demonstrated strong up-regulation by LPS of a large number of genes in the hypothalamus $(2,3,6)$. Here, when comparing the gene expression between LPS treated wild-type and mPGES-1 knockout mice, all genes differed less than three fold. This was not due to feeble gene response as such to LPS, as demonstrated by the very strong LPS-induced upregulation of Ptgs2, Lcn2 and cxcl10 (Table 3). Notably, while not recorded in the present study, the experimental set up used here, with similar dose and administration route of LPS, elicits robust fever $(5,10)$, pronounced anorexia (12), and strong hypothalamus-pituitary-adrenal axis activation (13). Although we in the present study did not validate with RT-qPCR on independent samples all genes that were differentially expressed in the microarray analysis, all genes which in that analysis showed a fold change $>2$ were examined, and with the exception for HSPs, to be discussed below, few displayed significant difference in expression between genotypes, and when such differences were present, they consisted, contrary to the microarray data, of down regulations that were in the order of $20-40 \%$.

The present data imply that genes that are strongly upregulated in the hypothalamus by peripheral immune stimuli (2-5) are not regulated by $\mathrm{PGE}_{2}$, but by some other, yet unidentified immune-to-brain signalling mechanism. They also seem to imply that the inflammation-induced gene expression in the brain, with the exception of that which results in $\mathrm{PGE}_{2}$ synthesis, cannot elicit many of the centrally evoked disease symptoms that are characteristic of inflammatory conditions, since they occur also in the absence of such symptoms, as we previously demonstrated in mPGES-1 knock-out mice (5). However, it cannot be excluded that such induced central gene expression still may be a necessary, although not sufficient, component for the sickness responses. 
Furthermore, the possibility exists that a $\mathrm{PGE}_{2}$-dependent induction of immediate-early genes was not detected considering that the expression analysis was performed $5 \mathrm{~h}$ after the immune stimulation. However, previous work in this laboratory has demonstrated that $c$-fos induction, which is prominent in many brain regions upon LPS-stimulation, including the preoptic hypothalamic regions, (13, 35), is independent of induced PGE $\mathrm{P}_{2}$-production (13). Thus, $c$-fos mRNA was rather increased in mPGES-1 KO mice in the hypothalamus $1 \mathrm{~h}$ after LPS injection compared to WT mice, and Fos protein expression was of the same magnitude in both genotypes several autonomic relay regions, including the preoptic hypothalamus, at 3 h post-injection (13); however, conflicting data exist (36, 37). Similarly, it cannot be excluded that transcriptional changes could occur at a later time point than $5 \mathrm{~h}$. However, $\mathrm{PGE}_{2}$ levels, which peak at $3 \mathrm{~h}$ post-injection, show a marked drop at $5 \mathrm{~h}$, and are back to baseline levels at $12 \mathrm{~h}$ (29). Hence, if little effect on mRNA expression is seen $2 \mathrm{~h}$ after peak $\mathrm{PGE}_{2}$ levels, i.e. the point examined in the present study, it seems unlikely that the considerably lower $\mathrm{PGE}_{2}$ levels that are present are later time points should induce such changes.

Our microarray analysis and qPCR validation identified two genes, Hspa1a and Hspa1b, that were induced in wild-type mice but not in mPGES-1 KO mice, and examination of the temporal pattern showed that these genes displayed induction in LPS challenged wild-type mice subsequent to the induction of mPGES-1 and hence subsequent to mPGES-1 induced $\mathrm{PGE}_{2}$ synthesis. However, examination of the ratio of expression between the hypothalamus and striatum revealed that only Hspa1b displayed a pattern similar to that of mPGES-1, i.e. larger induction in the hypothalamus than in the striatum, being consistent with the higher EP-receptor expression in this region, whereas Hspa1a showed the opposite pattern with a larger 
induction in the striatum than in the hypothalamus. These observations suggested that the HSP induction was not the result of intracellular signalling in EP-expressing cells upon ligand binding, but secondary to the resulting increased body temperature. This idea was further corroborated by the cage exchange stress experiment, which resulted in induction of the HSPs, without induction of $\mathrm{PGE}_{2}$-synthesizing enzymes. It is well in line with the role of HSPs to protect cellular proteins from denaturation under stressful conditions, including heat stress (38).

A possible limitation of the present study is that although a well-defined EP rich region was dissected (21), it contains a heterogeneous population of cells. Hence it is possible that the cell population in which transcriptional regulation might have occurred in response to $\mathrm{PGE}_{2}$ binding to its receptors may have constituted a tissue fraction too small to enable detection of moderate changes in gene expression in these cells. An alternative approach which would have yielded a more homogenous cell population would have been to dissect only EP expressing cells. Unfortunately, this was not possible because of the lack of suitable antibodies against the mouse EP receptor. However, in a study in the rat, Tsuchiya et al (39) microdissected $\mathrm{EP}_{3}$ expressing neurons 30 min after intracerebroventricular administration of $\mathrm{PGE}_{2}$. Microarray analysis identified 16 genes that were more than 1.5 fold changed, among them $\mathrm{GABA}_{\mathrm{A}}$ receptor subunits that showed decreased expression upon $\mathrm{PGE}_{2}$ stimulation. These results were not verified by present study, a difference which, in addition to different sensitivity of the methods used, also can be explained by the use of different stimuli used (PGE 2 icv vs. LPS ip) and the different time points chosen for analysis (30 min vs. 5 h).

Another potential limitation is the sensitivity of the microarray analysis. As noted in the results sections there were some discordant results when those from 
microarray and RT-qPCR are compared. In a recent study on LPS induced gene expression in the hypothalamus (6) we found for lipocalin-2 mRNA which displayed very strong upregulation as determined by RT-qPCR (several 100-fold) that the obtained value in the microarray analysis was about one order of magnitude lower, indicating a smaller dynamic range in the latter analysis. However, such a difference should not have influenced the present findings per se, since a smaller dynamic range in the microarray analysis would affect the analysis of LPS-induction in both genotypes in the same way. In fact, in our previous study, in which a genotype difference was found for the LPS- induced lipocalin-2 expression, this was of about the same magnitude in the microarray analysis as in the RT-qPCR, despite the fact that the obtained degree of upregulation vs. saline treated mice differed greatly between the two analyses. Furthermore, in the present study the relative difference in LPS-induction between genotypes for some genes that were strongly upregulated by LPS was about the same in the microarray analysis as in the RT-qPCR (Table 3).

In conclusion, the present gene expression study shows very small changes of the preoptic transcriptome that are mPGES-1 dependent. The genes that showed prominent mPGES-1 dependent upregulation, Hspa1a and Hspa1b, were proven to be temperature-dependent genes that had a general up-regulation in the whole brain, not controlled by mPGES-1 synthesized PGE 2 . Our data hence suggest that the centrally elicited disease symptoms, while being dependent on induced $\mathrm{PGE}_{2}$-synthesis that is dependent on mPGES-1 $(5,10,12,13,34)$, are not the result of transcriptional regulation in brain cells. Rather, they suggest that these symptoms come into being by regulation of neuronal excitability that is the consequence of intracellular, transcriptional independent cascades. Hence, while prostaglandins, and particularly $\mathrm{PGE}_{2}$, are considered to be critical intermediates for activation of the brain by a 
peripheral immune signals $(16,40)$, the profound gene regulatory effects elicited by such signals (2-6) must be mediated by other yet unidentified routes and are not directly involved in eliciting the centrally mediated sickness symptoms.

\section{Acknowledgements}

This study was supported by the Swedish Research Council (\#33X-07879, \#68X20535, \#61X-20535), the Swedish Cancer Foundation (\#4095), the Tore Nilsson Foundation, the Åke Wiberg Foundation, the Lars Hierta Memorial Foundation, the Magn. Bergvall Foundation, The Linköping Society of Medicine, County Council of Östergötland, the Harald and Greta Jeansson Foundation, the Royal Swedish. Author contributions: $\mathrm{AMV}, \mathrm{UK}$, and $\mathrm{CN}$ performed the research. $\mathrm{AMV}, \mathrm{AB}$, and $\mathrm{CN}$ designed the research; $\mathrm{AMV}, \mathrm{AB}$, and $\mathrm{CN}$ analysed the data; and $\mathrm{AMV}, \mathrm{AB}$, and $\mathrm{CN}$ wrote the paper.

\section{References}

1. Dantzer R, Bluthe RM, Gheusi G, Cremona S, Laye S, Parnet P, Kelley KW. Molecular basis of sickness behavior. Ann N Y Acad Sci 1998; 856: 132-138.

2. Reyes TM, Walker JR, DeCino C, Hogenesch JB, Sawchenko PE. Categorically distinct acute stressors elicit dissimilar transcriptional profiles in the paraventricular nucleus of the hypothalamus. J Neurosci 2003; 23: 5607-5616.

3. Mastronardi C, Whelan F, Yildiz OA, Hannestad J, Elashoff D, McCann SM, Licinio J, Wong M-L. Caspase 1 deficiency reduces inflammation-induced brain transcription. Proc Natl Acad Sci U S A 2007; 104: 7205-7210. 
4. Aid S, Langenbach R, Bosetti F. Neuroinflammatory response to lipopolysaccharide is exacerbated in mice genetically deficient in cyclooxygenase-2. J Neuroinflammation 2008; 5: 17.

5. Nilsberth C, Hamzic N, Norell M, Blomqvist A. Peripheral lipopolysaccharide administration induces cytokine mRNA expression in the viscera and brain of feverrefractory mice lacking microsomal prostaglandin E synthase-1. J Neuroendocrinol 2009; 21: 715-721.

6. Hamzic N, Blomqvist A, Nilsberth C. Immune-induced expression of lipocalin-2 in brain endothelial cells: relationship with interleukin-6, cyclooxygenase-2 and the febrile response. J Neuroendocrinol 2013; 25: 271-280.

7. Ek M, Engblom D, Saha S, Blomqvist A, Jakobsson PJ, Ericsson-Dahlstrand A. Inflammatory response: pathway across the blood-brain barrier. Nature 2001; 410: 430-431.

8. Yamagata K, Matsumura K, Inoue W, Shiraki T, Suzuki K, Yasuda S, Sugiura H, Cao C, Watanabe Y, Kobayashi S. Coexpression of microsomal-type prostaglandin E synthase with cyclooxygenase-2 in brain endothelial cells of rats during endotoxininduced fever. J Neurosci 2001; 21: 2669-2677.

9. Engstrom L, Rosen K, Angel A, Fyrberg A, Mackerlova L, Konsman JP, Engblom D, Blomqvist A. Systemic Immune Challenge Activates an Intrinsically Regulated Local Inflammatory Circuit in the Adrenal Gland. Endocrinology 2008; 149: $1436-1450$. 
10. Engblom D, Saha S, Engstrom L, Westman M, Audoly LP, Jakobsson PJ, Blomqvist A. Microsomal prostaglandin E synthase-1 is the central switch during immune-induced pyresis. Nat Neurosci 2003; 6: 1137-1138.

11. Pecchi E, Dallaporta M, Thirion S, Salvat C, Berenbaum F, Jean A, Troadec JD. Involvement of central microsomal prostaglandin E synthase-1 in IL-1beta-induced anorexia. Physiol Genomics 2006; 25: 485-492.

12. Elander L, Engstrom L, Hallbeck M, Blomqvist A. IL-1beta and LPS induce anorexia by distinct mechanisms differentially dependent on microsomal prostaglandin E synthase-1. Am J Physiol Regul Integr Comp Physiol 2007; 292: R258-267.

13. Elander L, Engstrom L, Ruud J, Mackerlova L, Jakobsson PJ, Engblom D, Nilsberth C, Blomqvist A. Inducible prostaglandin E2 synthesis interacts in a temporally supplementary sequence with constitutive prostaglandin-synthesizing enzymes in creating the hypothalamic-pituitary-adrenal axis response to immune challenge. J Neurosci 2009; 29: 1404-1413.

14. Vardeh D, Wang D, Costigan M, Lazarus M, Saper CB, Woolf CJ, Fitzgerald GA, Samad TA. COX2 in CNS neural cells mediates mechanical inflammatory pain hypersensitivity in mice. J Clin Invest 2009; 119: 287-294.

15. Elander L, Ruud J, Korotkova M, Jakobsson PJ, Blomqvist A. Cyclooxygenase-1 mediates the immediate corticosterone response to peripheral immune challenge induced by lipopolysaccharide. Neurosci Lett 2010; 470: 10-12. 
16. Engblom D, Ek M, Saha S, Ericsson-Dahlstrand A, Jakobsson PJ, Blomqvist A. Prostaglandins as inflammatory messengers across the blood-brain barrier. J Mol Med 2002; 80: 5-15.

17. Rudaya AY, Steiner AA, Robbins JR, Dragic AS, Romanovsky AA.

Thermoregulatory responses to lipopolysaccharide in the mouse: dependence on the dose and ambient temperature. Am J Physiol Regul Integr Comp Physiol 2005; 289: R1244-1252.

18. Engström L, Ruud J, Eskilsson A, Larsson A, Mackerlova L, Kugelberg U, Qian H, Vasilache AM, Larsson P, Engblom D, Sigvardsson M, Jönsson J-I, Blomqvist A. Lipopolysaccharide-induced fever depends on prostaglandin E2 production specifically in brain endothelial cells. Endocrinology 2012; 153: 4849-4861.

19. Jakobsson PJ, Thoren S, Morgenstern R, Samuelsson B. Identification of human prostaglandin E synthase: a microsomal, glutathione-dependent, inducible enzyme, constituting a potential novel drug target. Proc Natl Acad Sci U S A 1999; 96: 72207225.

20. Trebino CE, Stock JL, Gibbons CP, Naiman BM, Wachtmann TS, Umland JP, Pandher K, Lapointe JM, Saha S, Roach ML, Carter D, Thomas NA, Durtschi BA, McNeish JD, Hambor JE, Jakobsson PJ, Carty TJ, Perez JR, Audoly LP. Impaired inflammatory and pain responses in mice lacking an inducible prostaglandin E synthase. Proc Natl Acad Sci U S A 2003; 100: 9044-9049.

21. Vasilache AM, Andersson J, Nilsberth C. Expression of PGE(2) EP(3) receptor subtypes in the mouse preoptic region. Neurosci Lett 2007; 423: 179-183. 
22. Lazarus M, Yoshida K, Coppari R, Bass CE, Mochizuki T, Lowell BB, Saper

CB. EP3 prostaglandin receptors in the median preoptic nucleus are critical for fever responses. Nat Neurosci 2007; 10: 1131-1133.

23. Oka T, Oka K, Kobayashi T, Sugimoto Y, Ichikawa A, Ushikubi F, Narumiya S, Saper CB. Characteristics of thermoregulatory and febrile responses in mice deficient in prostaglandin EP1 and EP3 receptors. J Physiol 2003; 551: 945-954.

24. Nilsberth C, Elander L, Hamzic N, Norell M, Lonn J, Engstrom L, Blomqvist A. The role of interleukin-6 in lipopolysaccharide-induced fever by mechanisms independent of prostaglandin E2. Endocrinology 2009; 150: 1850-1860.

25. Irizarry RA, Hobbs B, Collin F, Beazer-Barclay YD, Antonellis KJ, Scherf U, Speed TP. Exploration, normalization, and summaries of high density oligonucleotide array probe level data. Biostatistics 2003; 4: 249-264.

26. Wu ZJ, Irizarry RA, Gentleman R, Martinez-Murillo F, Spencer F. A modelbased background adjustment for oligonucleotide expression arrays. JASA 2004; 99: 909-917.

27. Affymetrix. Guide to Probe Logarithmic Intensity Error (PLIER) Estimation. http://media.affymetrix.com/support/technical/technotes/plier_technote.pdf

28. Tung Y-CL, Ma M, Piper S, Coll A, O'Rahilly S, Yeo GSH. Novel leptinregulated genes revealed by transcriptional profiling of the hypothalamic paraventricular nucleus. J Neurosci 2008; 28: 12419-12426.

29. Inoue W, Matsumura K, Yamagata K, Takemiya T, Shiraki T, Kobayashi S. Brain-specific endothelial induction of prostaglandin E(2) synthesis enzymes and its temporal relation to fever. Neurosci Res 2002; 44: 51-61. 
30. Konsman JP, Vigues S, Mackerlova L, Bristow A, Blomqvist A. Rat brain vascular distribution of interleukin-1 type-1 receptor immunoreactivity: Relationship to patterns of inducible cyclooxygenase expression by peripheral inflammatory stimuli. J Comp Neurol 2004; 472: 113-129.

31. Zhang J, Rivest S. Distribution, regulation and colocalization of the genes encoding the EP2- and EP4-PGE2 receptors in the rat brain and neuronal responses to systemic inflammation. Eur J Neurosci 1999; 11: 2651-2668.

32. Ek M, Arias C, Sawchenko P, Ericsson-Dahlstrand A. Distribution of the EP3 prostaglandin $\mathrm{E}(2)$ receptor subtype in the rat brain: relationship to sites of interleukin-1-induced cellular responsiveness. J Comp Neurol 2000; 428: 5-20.

33. Saha S, Engstrom L, Mackerlova L, Jakobsson PJ, Blomqvist A. Impaired febrile responses to immune challenge in mice deficient in microsomal prostaglandin $\mathrm{E}$ synthase-1. Am J Physiol Regul Integr Comp Physiol 2005; 288: R1100-1107. 34. Fritz M, Klawonn AM, Wilhelms D, Örtegren U, Ridder DA, Hamzic N, Nilsberth C, Schwaninger M, Blomqvist A, Engblom D. The affective component of systemic inflammation - a new role for prostaglandins. Soc Neurosci Abstr 2012: 587.512

35. Elmquist JK, Scammell TE, Jacobson CD, Saper CB. Distribution of Fos-like immunoreactivity in the rat brain following intravenous lipopolysaccharide administration. J Comp Neurol 1996; 371: 85-103.

36. Dallaporta M, Pecchi E, Jacques C, Berenbaum F, Jean A, Thirion S, Troadec JD. c-Fos immunoreactivity induced by intraperitoneal LPS administration is reduced in 
the brain of mice lacking the microsomal prostaglandin E synthase-1 (mPGES-1). Brain Behav Immun 2007; 21: 1109-1121.

37. Zhang YH, Lu J, Elmquist JK, Saper CB. Specific roles of cyclooxygenase-1 and cyclooxygenase-2 in lipopolysaccharide-induced fever and Fos expression in rat brain. J Comp Neurol 2003; 463: 3-12.

38. Cosgrove JW, Brown IR. Heat shock protein in mammalian brain and other organs after a physiologically relevant increase in body temperature induced by Dlysergic acid diethylamide. Proc Natl Acad Sci U S A 1983; 80: 569-573.

39. Tsuchiya H, Oka T, Nakamura K, Ichikawa A, Saper CB, Sugimoto Y. Prostaglandin E2 Attenuates Preoptic Expression of GABAA Receptors via EP3 Receptors. J Biol Chem 2008; 283: 11064-11071.

40. Saper CB, Romanovsky AA, Scammell TE. Neural circuitry engaged by prostaglandins during the sickness syndrome. Nat Neurosci 2012; 15: 1088-1095. 


\section{Legend to Figures}
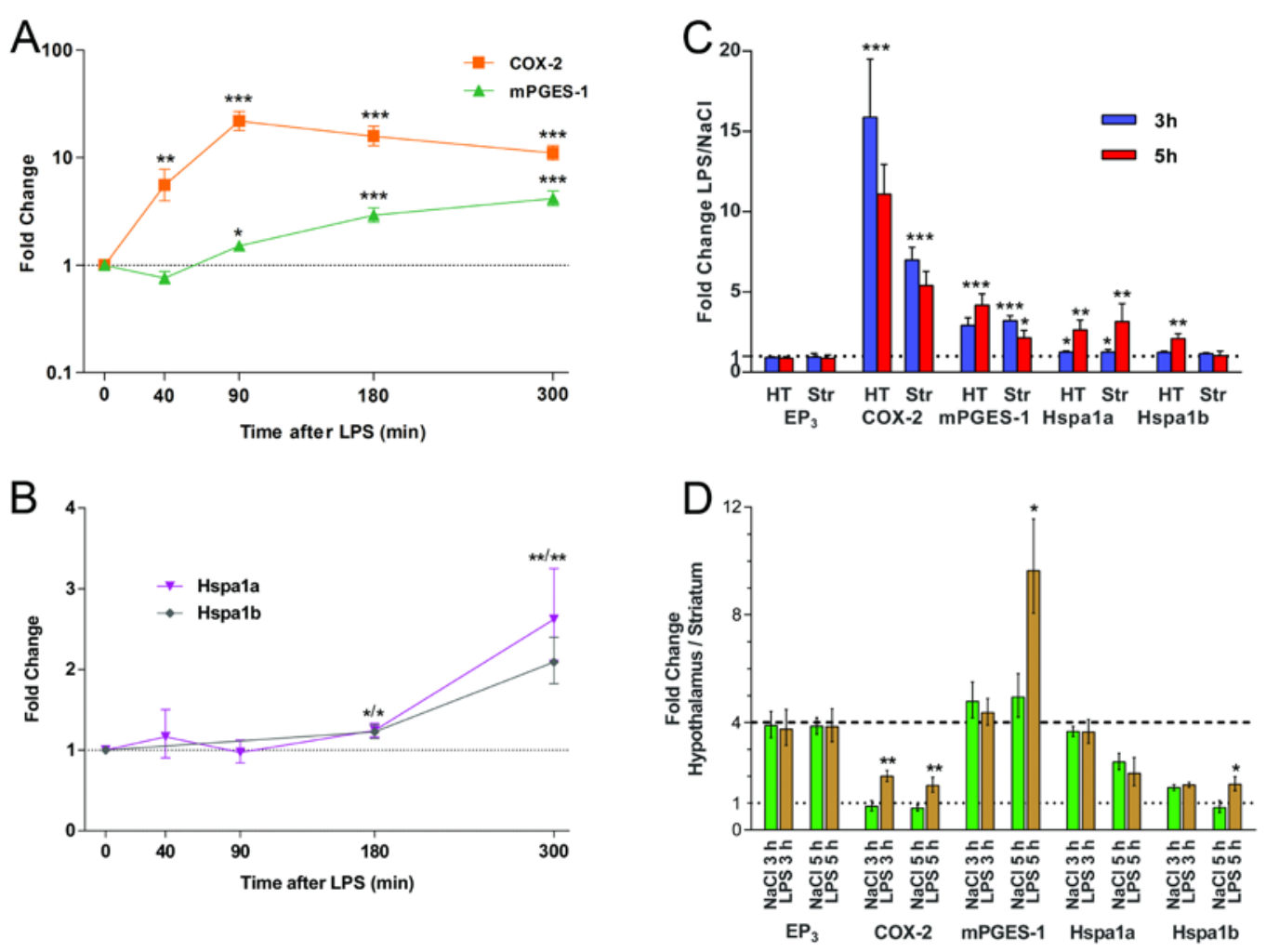

Figure 1. (A) Time course for LPS-induced gene expression of the $\mathrm{COX}_{2}$ and mPGES-1 in the hypothalamus. Fold changes are related to the expression of saline injected mice killed at the corresponding time point. (B) LPS-induced expression of Hspa1a/b in the hypothalamus of wild-type mice. (C) LPS-induced expression of $\mathrm{EP}_{3}$, COX-2, mPGES-1, HSPa1a, and HSPa1b in the hypothalamus and striatum of wildtype mice at $3 \mathrm{~h}$ and $5 \mathrm{~h}$ after injection. (D) Relationship between LPS-induced expression in the hypothalamus (HT) and striatum (Str) of $\mathrm{EP}_{3}$, COX-2, mPGES-1, HSPa1a, and HSPa1b in wild-type mice. *, **, *** indicate $P<0.05, P<0.01$, and $P$ $<0.001$ vs. control animals. $n=5-6$ in A and $n=6$ in B-D. 

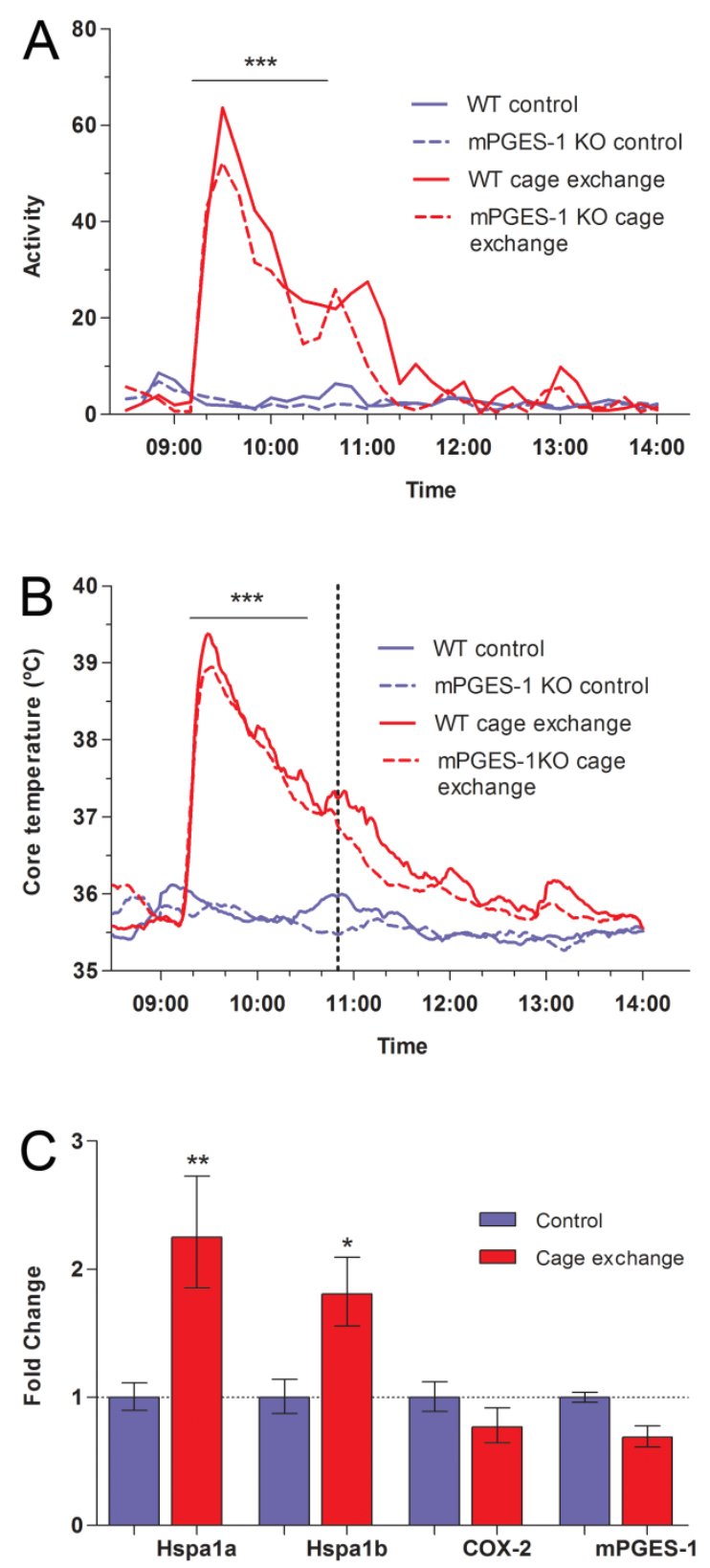

Figure 2. (A) Activity and (B) temperature responses to cage exchange stress compared with controls. Vertical line at $100 \mathrm{~min}$ indicates the time for gene expression analysis. (C) RT-qPCR on Hspa1a/b, Cox-2 and mPGES-1 expression after cage exchange. * ${ }^{* *}$, *** indicate $P<0.05, P<0.01$, and $P<0.001$ vs. control animals. Data for Hspa1a/b and Cox-2 are pooled from wild-type and mPGES-1 KO mice $(n=3+3)$; data for mPGES-1 are from wild-type mice only $(n=3)$. 
Table 1 TaqMan ${ }^{\circledR}$ Gene Assays used for RT-qPCR

\begin{tabular}{llll} 
Anks1b & Mm00619343_m1 & Klhl7 & Mm00518218_m1 \\
Appl1 & Mm00507526_m1 & Lcn2 & Mm01324470_m1 \\
Atf2 & Mm00833804_g1 & Nrxn3 & Mm00553213_m1 \\
Atp1b1 & Mm00437612_m1 & Nts & Mm00481140_m1 \\
Becn1 & Mm01265461_m1 & Obfc2a & Mm01256791_m1 \\
C1ql3 & Mm00655312_m1 & Olfm3 & Mm00462529_m1 \\
Calm1 & Mm00486655_m1 & Pcdh7 & Mm00479579_m1 \\
Cnr1 & Mm00432621_s1 & Pcdhb20 & Mm00474589_s1 \\
Creb1 & Mm00501607_m1 & Pde10a & Mm00449332_m1 \\
CXCL10 & Mm00445235_m1 & Pdzd2 & Mm01308962_m1 \\
Dlgap1 & Mm00510688_m1 & Ppp3ca & Mm01317678_m1 \\
Dnm1l & Mm01342903_m1 & Prkar2b & Mm01293022_m1 \\
Epha4 & Mm00433056_m1 & Prpf4b & Mm00443401_m1 \\
EP3 & Mm01316856_m1 & Psip1 & Mm00505918_m1 \\
Fam179b & Mm00625476_m1 & Ptges & Mm00452105_m1 \\
Gabra4 & Mm00802631_m1 & Ptgs2 & Mm00478374_m1 \\
Gabrb2 & Mm00549788_s1 & Ptprg & Mm00477264_m1 \\
Gabrg1 & Mm00439047_m1 & Rab40b & Mm00454800_m1 \\
Gabrg2 & Mm00433489_m1 & Rbm41 & Mm00463854_m1 \\
Gad1 & Mm00725661_s1 & Shh & Mm03053649_s1 \\
Gapdh & Mm99999915_g1 & Snap91 & Mm00489016_m1 \\
Glrb & Mm00439140_m1 & Snca & Mm00447333_m1 \\
Gucy1b3 & Mm00516926_m1 & Strn & Mm00448910_m1 \\
Hspa1a & Mm01159846_s1 & Synj2bp;Cox16 & Mm00777406_m1 \\
Hspa1b & Mm03038954_s1 & Synpr & Mm00511114_m1 \\
Kcnab1 & Mm00440018_m1 & Tac1 & Mm01166996_m1 \\
& & & \\
\hline
\end{tabular}


Table 2 Gene expression in a 48-format TaqMan Low Density Array on LCM dissected material compared with Affymetrix data

\begin{tabular}{|c|c|c|c|c|c|c|}
\hline \multirow{2}{*}{$\begin{array}{l}\text { Gene } \\
\text { Symbol }\end{array}$} & \multirow{2}{*}{$\begin{array}{l}\text { Affymetrix } \\
\text { Probe Set ID }\end{array}$} & \multirow{2}{*}{$\begin{array}{l}\text { FC Affymetrix } \\
\text { LPS WT/KO }\end{array}$} & \multicolumn{4}{|l|}{ FC RT-qPCR } \\
\hline & & & LPS WT/KO & WT LPS/NaCl & KO LPS/NaCl & $\mathrm{NaCl} \mathrm{WT} / \mathrm{KO}$ \\
\hline Anks1b & 1460449_at & 2.054 & $0.808^{* *}$ & 0.982 & 1.134 & 0.933 \\
\hline Appl1 & 1436116_x_at & 1.517 & 0.931 & 0.919 & 1.052 & 1.065 \\
\hline Atf2 & 1426583_at & 2.05 & 0.903 & 0.963 & 1.066 & 1 \\
\hline Atp1b1 & 1439036_a_at & 2.01 & 0.971 & 0.954 & 1.002 & 1.02 \\
\hline Becn1 & 1455880_s_at & 2.697 & 0.929 & 1.021 & 1.058 & 0.963 \\
\hline C1ql3 & 1451620_at & 2.168 & 0.847 & 0.856 & 1.143 & 1.131 \\
\hline Calm1 & 1433592_at & 1.601 & $0.822^{*}$ & 1.038 & 1.098 & 0.87 \\
\hline Cnr1 & 1434172_at & 1.865 & 0.998 & 1.082 & 1.129 & 1.041 \\
\hline Creb1 & 1428755_at & 1.521 & 1.049 & 1.046 & 1.104 & 1.107 \\
\hline Dlgap1 & 1436076_at & 1.735 & 0.898 & 1.03 & 1.111 & 0.969 \\
\hline Dnm1l & 1428086_at & 1.692 & 0.941 & 1.092 & 1.132 & 0.976 \\
\hline Epha4 & 1429021_at & 2.073 & 0.886 & 1.083 & 1.169 & 0.956 \\
\hline Fam179b & 1434843_at & 2.034 & $0.697^{*}$ & $0.623^{* *}$ & 0.869 & 0.973 \\
\hline Gabra4 & 1433707_at & 1.795 & 0.917 & 1.067 & 1.06 & 0.911 \\
\hline Gabrb2 & 1429685_at & 1.792 & 1.007 & 0.945 & 0.963 & 1.026 \\
\hline Gabrg1 & 1460408_at & 1.316 & 0.907 & 0.839 & 1.143 & $1.237^{*}$ \\
\hline Gabrg2 & 1418177_at & 1.677 & 0.990 & 0.935 & 1.02 & 1.08 \\
\hline Gad1 & 1416561_at & 2.342 & 1.009 & 1.066 & 1.076 & 1.019 \\
\hline Glrb & 1422504_at & 1.789 & 0.938 & 0.896 & 1.012 & 1.059 \\
\hline Gucy1b3 & 1420872_at & 1.845 & 0.942 & 0.998 & 1.056 & 0.997 \\
\hline Hspa1a & 1452388_at & 1.515 & $3.487^{* * *}$ & $4.591 * \star \star$ & 1.169 & 1.126 \\
\hline Kcnab1 & 1448468_a_at & 2.256 & 0.841 & 1.122 & 1.117 & 0.837 \\
\hline Klhl7 & 1428091_at & 2.342 & 1.053 & 1.124 & 1.1 & 1.03 \\
\hline Nrxn3 & 1433788_at & 1.508 & 1.152 & 0.963 & 1.182 & $1.414^{\star *}$ \\
\hline Nts & 1422860_at & 1.51 & 0.824 & 0.829 & 1.141 & 1.134 \\
\hline Obfc2a & 1452203_at & 2.223 & 0.848 & 0.983 & 1.169 & 1.008 \\
\hline Olfm3 & 1452090_a_at & 2.15 & 0.875 & 0.853 & 1.097 & 1.125 \\
\hline Pcdh7 & 1437442_at & 1.535 & 0.791 & 0.777 & 1.038 & 1.057 \\
\hline Pcdhb20 & 1449583_at & 1.844 & 0.965 & $0.809 *$ & 1.053 & $1.257^{*}$ \\
\hline Pde10a & 1439618_at & 2.282 & 0.845 & 1.101 & 1.137 & 0.873 \\
\hline $\mathrm{Pdzd} 2$ & 1435553_at & 2.314 & 1.001 & $1.47^{*}$ & $1.586^{*}$ & 1.081 \\
\hline Ptges & 1439747_at & - & - & $2.745^{\star *}$ & - & - \\
\hline Рpp3ca & 1426401_at & 1.666 & 0.854 & 1.046 & 1.147 & 0.935 \\
\hline Prkar2b & 1438664_at & 1.689 & 1.038 & 1.009 & 1.03 & 1.061 \\
\hline Prpf4b & 1425498_at & 2.062 & 0.935 & 1.017 & 1.109 & 1.02 \\
\hline Psip1 & 1460403_at & 2.123 & 0.945 & 0.943 & 1.1 & 1.103 \\
\hline Ptprg & 1434360_s_at & 2.832 & 0.897 & 0.855 & 1.2 & $1.259^{*}$ \\
\hline Rab40b & 1436566_at & 2.056 & $0.811^{*}$ & $1.187^{*}$ & $1.311^{* *}$ & 0.896 \\
\hline Rbm41 & 1456027_at & 2.036 & 1.091 & 1.15 & 0.996 & 0.945 \\
\hline Shh & 1436869_at & 1.755 & 1.148 & 0.908 & $0.798^{*}$ & 1.01 \\
\hline Snap91 & 1416688_at & 1.782 & 0.982 & 0.963 & 1.062 & 1.083 \\
\hline Snca & 1436853_a_at & 1.706 & 0.971 & 1.191 & 1.07 & 0.872 \\
\hline Strn & 1455156_at & 1.579 & 0.918 & 1.073 & 1.208 & 1.033 \\
\hline Synj2bp & 1417834_at & 2.027 & 1.004 & 1.021 & 1.102 & 1.084 \\
\hline Synpr & 1423640_at & 1.679 & 0.787 & 1.01 & 1.105 & 0.861 \\
\hline Tac1 & 1416783_at & 2.777 & 0.845 & 1.11 & 1.106 & 0.842 \\
\hline
\end{tabular}

Significant differences are in bold. *, **, and *** indicate $P<0.05,0.01$, and 0.001 , respectively. FC, fold change; KO, mPGES-1 knockout; LCM, laser capture microdissection; LPS, lipopolysaccharide; WT, wild-type. Fold change values are the quotient between genotypes or treatments. 
Vasilache et al., page 29

Table 3 RT-qPCR on LCM dissected material compared with Affymetrix data

\begin{tabular}{|c|c|c|c|c|c|c|}
\hline \multirow{2}{*}{$\begin{array}{l}\text { Gene } \\
\text { Symbol }\end{array}$} & \multirow{2}{*}{$\begin{array}{l}\text { Affymetrix } \\
\text { Probe Set ID }\end{array}$} & FC Affymetrix & \multicolumn{4}{|l|}{ FC RT-qPCR } \\
\hline & & LPS WT/KO & LPS WT/KO & WT LPS/NaCl & KO LPS/NaCl & $\mathrm{NaCl} \mathrm{WT} / \mathrm{KO}$ \\
\hline & 1427126_at & $2.377^{\star \star}$ & & & & \\
\hline Hspa1b & $\begin{array}{l}1427127 \text { - x at } \\
1452318 \text { a at }\end{array}$ & $\begin{array}{l}2.283^{\star \star} \\
2.051^{\star \star *}\end{array}$ & $1.768^{*}$ & $1.533^{*}$ & 0.922 & 1.064 \\
\hline Cxcl10 & 1418930_at & 0.693 & 0.271 & $154.6^{* * *}$ & $494.8^{\star \star \star}$ & 0.870 \\
\hline Lcn2 & 1427747_a_at & 0.793 & 1.115 & $533.2^{* * *}$ & $314.5^{\star \star \star}$ & 0.658 \\
\hline Ptgs2 & 1417263 at & 0.958 & 0.586 & $10.19 * \star *$ & $16.81^{\star *}$ & 0.968 \\
\hline
\end{tabular}

Significant differences are in bold. *, **, and *** indicate $P<0.05,0.01$, and 0.001 , respectively. FC, fold change; KO, mPGES-1 knockout; LCM, laser capture microdissection; LPS, lipopolysaccharide; WT, wild-type. Fold change values are the quotient between genotypes or treatments. 